\title{
Anopheles gambiae densovirus (AgDNV) has negligible affects on adult survival and transcriptome of its mosquito host
}

Mosquito densoviruses (DNVs) are candidate agents for paratransgenic control of malaria and other vector-borne diseases. Unlike other mosquito DNVs, the Anopheles gambiae DNV (AgDNV) is non-pathogenic to larval mosquitoes. However, the cost of infection upon adults and the molecular mechanisms underpinning infection in the mosquito host are unknown. Using life table analysis, we show that AgDNV infection has minimal effects on An. gambiae survival (no significant effect in 2 replicates and a slight 2 day survival decrease in the third replicate). Using microarrays, we show that AgDNV has very minimal effect on the adult mosquito transcriptome, with only 4-15 genes differentially regulated depending on the statistical criteria imposed. The minimal impact upon global transcription provides some mechanistic understanding of lack of virus pathogenicity, suggesting a long co-evolutionary history that has shifted towards avirulence. From an applied standpoint, lack of strong induced fitness costs makes AgDNV an attractive agent for paratransgenic malaria control. 
1 Anopheles gambiae densovirus (AgDNV) has negligible

2 affects on adult survival and transcriptome of its mosquito

3 host

4 Xiaoxia Ren ${ }^{2 \pi}$, Grant L. Hughes ${ }^{1 \pi}$, Guodong Niu ${ }^{1,3}$ Yasutsugu Suzuki ${ }^{1}$ and Jason L. Rasgon $51 *$

61 The Department of Entomology, Center for Infectious Disease Dynamics, and the Huck

7 Institutes of the Life Sciences, Pennsylvania State University, University Park, Pennsylvania

$8 \quad 16802$.

$9 \quad 2$ Pharmaceutics International Inc., Hunt Valley, MD 21031.

103 Current address: Department of Chemistry and Biochemistry, University of Oklahoma,

$11 \quad$ Norman, OK 73019.

12 T These authors contributed equally to this work.

13 * Author to whom correspondence should be addressed; E-Mail: jlr54@psu.edu, tel +1 410-812-

$14 \quad 9410$ 


\section{Abstract}

16 Mosquito densoviruses (DNVs) are candidate agents for paratransgenic control of malaria and

17 other vector-borne diseases. Unlike other mosquito DNVs, the Anopheles gambiae DNV

18 (AgDNV) is non-pathogenic to larval mosquitoes. However, the cost of infection upon adults and

19 the molecular mechanisms underpinning infection in the mosquito host are unknown. Using life

20 table analysis, we show that AgDNV infection has minimal effects on An. gambiae survival (no

21 significant effect in 2 replicates and a slight 2 day survival decrease in the third replicate). Using

22 microarrays, we show that AgDNV has very minimal effect on the adult mosquito transcriptome,

23 with only 4-15 genes differentially regulated depending on the statistical criteria imposed. The

24 minimal impact upon global transcription provides some mechanistic understanding of lack of

25 virus pathogenicity, suggesting a long co-evolutionary history that has shifted towards avirulence.

26 From an applied standpoint, lack of strong induced fitness costs makes AgDNV an attractive

27 agent for paratransgenic malaria control. 


\section{Introduction}

29 Human malaria infects up to 500 million people per year and causes almost 3 million deaths annually (Hay et al., 2004). Traditional control strategies that target the mosquito vector (such as

31 insecticides) are becoming less effective due to the emergence of resistance (Enayati and Hemingway, 2011). Therefore, there is a concerted effort to develop novel strategies to combat arthropod-borne diseases. One such strategy is to use microbes to manipulate components of host vector competence. While some microbes can either directly or indirectly affect Plasmodium development in the host (Cirimotich et al., 2011; Ricci et al., 2011; Hughes et al., 2011a, Hughes paratransgenic malaria control, the microorganism should not significantly compromise the host et al. 2014), the genetic modification of mosquito symbiotic microorganisms with effector molecules which inhibit pathogens (paratransgenesis) has been proposed as one novel method to control malaria (Favia et al., 2007; Wang et al., 2012). To be a microbial candidate for

41 Rosales and Durvasula, 2002). 
42 Densonucleosis viruses (or densoviruses [DNVs]) are icosahedral, non-enveloped parvoviruses that have been identified from many invertebrate taxa, including multiple mosquito species (Boublik, Jousset and Bergoin, 1994; Jousset, Baquerizo and Bergoin, 2000; Ledermann et al., 2004; Carlson, Suchman and Buchastsky, 2006; Ren, Hoiczyk and Rasgon, 2008; Zhai et al., 2008, Ng et al. 2011). DNVs are easily to manipulate and are candidate agents for paratransgenic control of vector-borne diseases by expression of toxins or anti-pathogen effector molecules (Ren, Hoiczyk and Rasgon, 2008). Mosquito DNVs are generally lethal to young larvae but are tolerated by older larvae, which develop into infected adults that complete the pathogen life cycle by inoculating virus into the aquatic larval environment (Carlson, Suchman and Buchastsky, 2006). Unlike the Aedes aegypti densovirus (AeDNV), which is generally lethal to young larvae and virulent to adults in a dose-dependent manner (Ledermann et al., 2004), the An. gambiae densovirus (AgDNV) has minimal pathogenic effects in larvae (Ren, Hoiczyk and Rasgon, 2008). In contrast to AeDNV, AgDNV does not replicate substantially in the immature or early adult life stages of An. gambiae, perhaps explaining minimal larval virulence. Instead, AgDNV replicates preferentially in adult mosquitoes (Ren and Rasgon, 2010).

To further evaluate the suitability of AgDNV for use in a paratransgenic malaria control strategy we studied the effect of infection on adult An. gambiae mosquitoes. By examining life history traits and the transcriptomic response of Anopheles mosquitoes to AgDNV infection we found minimal impact of AgDNV upon the mosquito host at the molecular level or upon adult fitness. Taken together, these data suggest that AgDNV could be a useful agent for paratransgenesis in An. gambiae mosquitoes as there is minimal fitness or transcriptome impact on the host after infection. 


\section{Materials and Methods}

Cell culture, mosquito infection and rearing conditions: Sua5B cells, which are naturally infected with AgDNV (Ren, Hoiczyk and Rasgon, 2008), were passaged weekly in Schneider's media with 10\% FBS. AgDNV was obtained from the infected cell line Sua5B and first-instar mosquito larvae infected by exposure to purified virus as previously described (Ren, Hoiczyk and Rasgon, 2008). Control mosquitoes were mock infected with Schneider's medium. After infection, mosquitoes were reared in $2 \mathrm{~L}$ pans according to a standard feeding protocol as described (Ren and Rasgon 2010).

Life-table analysis: At the pupal stage, cups of emerging pupae were placed in cages and removed 12 hours later ensuring that adults were of similar ages. Mosquitoes were allowed access to $10 \%$ sucrose but were not blood fed. Mortality was accessed daily at the same time \pm 1 hr. There were 3-4 cages per treatment (approximately 50 mosquitoes per cage), and the entire experiment was replicated three times (total $=740$ AgDNV-infected mosquitoes, 860 control mosquitoes). For AgDNV treatments, collected dead mosquitoes were assayed for AgDNV infection by PCR amplification of a $\sim 300$ bp fragment of the AgDNV capsid gene as described (Ren, Hoiczyk and Rasgon, 2008); infection rates per cage ranged from $87 \%$ - 100\%. The experiment included both males and females, but mosquitoes were not sexed for analysis. Data were analyzed by the Gehan-Breslow-Wilcoxon test using GraphPad Prism 5.

RNA extraction and Microarrays: Affymetrix GeneChip microarrays were used to assess the effect of AgDNV infection on An. gambiae gene transcription. First instar larvae were infected or mock infected as described above and reared to adulthood. At 10 days post-emergence when 
AgDNV titers are at their highest (Ren and Rasgon 2010) mosquitoes were processed for analysis. For each biological replicate, pools of 20 adult mosquitoes were processed (mosquitoes were not sexed). There were three replicates per treatment. 20 randomly selected mosquitoes per replicate were tested by PCR (Ren, Hoiczyk and Rasgon, 2008) to confirm AgDNV infection; $100 \%$ of mosquitoes treated with virus as larvae were positive for infection by PCR compared to 0\% of control mosquitoes. Mosquitoes were homogenized and lysed with Lysing Matrix D (MP bio) in $1 \mathrm{ml}$ of Trizol reagent (Invitrogen) by rapid agitation in a FastPrep 120 Instrument (MP Biomedicals, Solon, $\mathrm{OH}$ ) for 45 seconds at speed setting 6 and placed on ice for 2 minutes. Homogenization and ice incubation was repeated twice or until the samples were completely homogenized. After homogenization, RNA was extracted, purified and quantified as previously described (Hughes et al. 2011b). For each array 100ng total RNA was hybridized to the Affymetrix Plasmodium/Anopheles microarray using the Affymetrix 3' IVT express kit, according to manufacturer's recommended protocol. Hybridization cocktails were prepared as recommended for arrays of Standard format using reagents in the Affymetrix Hybridization, Wash, and Stain kit. Hybridization was performed at $45^{\circ} \mathrm{C}$ for 16 hours at $60 \mathrm{rpm}$ in the Affymetrix rotisserie hybridization oven. The signal amplification protocol for washing and staining of eukaryotic targets was performed in an automated fluidics station (Affymetrix FS450) using Affymetrix protocol FS450_0004. Arrays were transferred to a GCS3000 laser scanner with autoloader and 3G upgrade (Affymetrix) and scanned at an emission wavelength of 570nm at 2.5um resolution. Quality assessment of hybridizations and scans was performed with Expression Console software. Detailed analyses were performed using Partek Genomics Suite version 6.4. GC-RMA algorithm defaults were used for background correction, normalization and summarization of probesets. Analysis of variance (AVOVA) was performed with linear contrasts for each densovirus treatment vs. control. Gene lists were developed based on 1.75 or 2.0 fold change (FC) or greater gene expression using a false discovery rate of $\mathrm{P}<0.05$. 
110 Affymetrix CEL files are available as supplementary data at 111 http://rasgonlab.files.wordpress.com/2014/08/renetalrawaffymetrixdata.zip (controls: W1.CEL, 112 W2.CEL, W3.CEL; treatment: AgDNV1.CEL, AgDNV2.CEL, AgDNV3.CEL).

113 qPCR validation of microarray analysis: qPCR analysis was completed as previously 114 described (Hughes et al., 2011b). Briefly, RNA was extracted from pools of ten mosquitoes either 115 infected with densovirus or uninfected using an RNeasy mini kit (Qiagen). Five biological 116 replicates were completed for each treatment. RNA was DNase treated (Ambion) and cDNA 117 synthesized using superscript III (Invitrogen) following manufactures guidelines. qPCR was 118 completed using a Rotor gene Q (Qiagen) using Rotor gene SYBR green PCR kit (Qiagen) 119 according to manufactures guidelines. To validate microarray results we assayed five genes 120 selected both from genes affected and not affected in the microarray analysis (AMMECR1, Rel1, 121 Rel2, cactus and caspar; primers in Table 1). Expression of each target gene was normalizing to 122 expression of the ribosomal protein S7 gene (Table 1). All qPCRs were performed in triplicate. 123 Melt curve analysis was completed on all PCRs. Determinations of relative expression were 124 calculated using qGENE (Joehanes and Nelson, 2008).

\section{Results and Discussion}

Life table analysis: We used life table analysis to assess the fitness effects of AgDNV

127 infection on adult An. gambiae (Keele strain) mosquitoes. For replicates 1 and 2, survival 128 trajectories of AgDNV infected and uninfected mosquitoes were not significantly different 129 (Table 2, Figure 1A, 1B). For replicate 3, mosquitoes in both treatments had significantly 130 elevated mortality compared to replicates 1 and 2, and AgDNV-infected mosquitoes had a 131 slight, but statistically significant reduction in lifespan $(\mathrm{P}=0.003)$ (Table 2, Figure 1C). We 
132 do not know why results from replicate 3 differed from replicates 1 and 2 , but the 133 significant reduction (greater than 50\%) in lifespan for both treatments in replicate 3 134 suggests other confounding factors besides AgDNV infection are at play.

135 Microarray analysis: To evaluate the effect of AgDNV infection on host gene expression, 136 we completed microarray analysis comparing infected versus uninfected adult mosquitoes. 137 AgDNV infection had very limited effect on An. gambiae gene expression with global 138 expression analysis identifying only 4 genes modestly differentially up-regulated (fold139 change $[\mathrm{FC}] \square 2, \mathrm{P}<0.05)$ in response to infection, and no genes significantly down140 regulated (Table 3). qPCR of selected genes showed similar results $\left(\mathrm{R}^{2}=0.84, \mathrm{P}=0.03\right.$; 141 Figure 2). These results are in stark contrast to the effect of the human pathogen O'Nyong142 nyong virus in An. gambiae, where infection resulted in the regulation of 253 genes (152 up-regulated, 102 down-regulated), including many genes involved in anti-viral and innate 144 immune pathways (Waldock, Olson and Christophides, 2012). However, our results are 145 similar to other studies examining gene expression in response to DNV infection in other 146 insects. Minimal effects on host gene expression were seen in the moth Spodoptera 147 frugiperda with the up-regulation of only 8 genes after injection of DNV into fat body 148 tissue (Barat-Houari et al., 2006). Using subtractive hybridization to identify differentially 149 expressed genes in Bombyx mori in response to virus infection, only 28 genes were found in 150 a moth line resistant to DNV, while infection in susceptible line lead to differential 151 expression of 23 genes (Bao et al. 2008). While infection with other microbes profoundly 152 affects gene expression in An. gambiae (Abrantes et al., 2008), AgDNV (and DNVs in 153 general) seem to neither strongly elicit nor suppress global gene expression patterns. 
154 Further studies are required to ascertain whether the virus employs mechanism(s) to avoid 155 modulating the host transcriptome.

156 Of the 4 genes marginally up-regulated by AgDNV infection, two are putatively associated 157 with stress response (cytochrome P450 [CYP450] and AMME syndrome candidate gene 1 158 [AMMECR1]). In mosquitoes, CYP450s are detoxification enzymes expressed when the 159 insect is under oxidative stress (Feyereisen, 1999) and are known to be expressed when the involved in hydrolysis of peptide bonds during bloodmeal digestion (Noriega et al. 1996) while plugin is one of the major components of the mating plug (Le et al., 2013).

When we applied a less stringent FC criteria (1.75 FC), 15 genes were differently regulated in response to DNV virus infection (Table 3) with 9 genes up-regulated and 6 downregulated. Besides functionally unknown genes, the rest of the genes are classified to transport-, metabolism- or binding-related transcripts (Table 3).

Paratransgenesis is an approach that attempts to modulate vector competence of the vector 170 by manipulation of microorganisms within the host (Beard, Cordon-Rosales and Durvasula, 171 2002; Riehle and Jacobs-Lorena 2005). Malaria researchers have focused on 172 paratransgenesis as a novel alternative to traditional transgenic strategies (Favia et al., 
173 2007). Our results suggest that AgDNV infection has minimal impact on survival or gene

174 expression of its mosquito host making it a potentially attractive agent for paratransgenesis

175 in An. gambiae. It should be noted that survival is only one component of the complex

176 amalgam of traits that, collectively make up "fitness" and that further studies need to be

177 performed to assess the effect of AgDNV infection on other fitness components (such as

178 development time, fecundity, and mating behavior).

179 Acknowledgments

180 We thank the Johns Hopkins Malaria Research Institute Gene Array Core Facility (JHMRI181 GACF) for assistance with microarrays.

182 Figure legends

183 Figure 1. Survival of AgDNV infected or uninfected adult Anopheles gambiae. Mosquitoes 184 infected at the larvae stage with AgDNV purified from Sua5B cells (or mock infection as 185 control; WT) were assessed for adult survivorship every 24 hours until until all the 186 mosquitoes had perished. A, B and C refer to replicates 1, 2 and 3 respectively.

Figure 2. Validation of microarray data in DNV-infected adult An. gambiae mosquitoes. $188 \log _{2}$ fold change values for both microarray and qPCR methods were compared for 5 189 selected An. gambiae genes (AMMECR1, Rel1, Rel2, cactus and caspar). P =0.03. 


\section{References}

Abrantes P, Dimopoulos G, Grosso AR, do Rosário VE, Silveir, H. 2008. Chloroquine Mediated Modulation of Anopheles gambiae Gene Expression. PLoS ONE 3:e2587.

Bao YY, Li MW, Zhao YP, Ge JQ, Wang CS, Huang YP, Zhang CX. 2008. Differentially expressed genes in resistant and susceptible Bombyx mori strains infected with a densonucleosis virus. Insect Biochemistry and Molecular Biology 38:853-861.

Barat-Houari M, Hilliou F, Jousset FX, Sofer L, Deleury E, Rocher J, Ravallec M, Galibert L, Delobel P, Feyereisen R, Fournier P, Volkoff AN. 2006. Gene expression profiling of Spodoptera frugiperda hemocytes and fat body using cDNA microarray reveals polydnavirus-associated variations in lepidopteran host genes transcript levels. BMC Genomics 7:160.

Beard CB, Cordon-Rosales C, Durvasula RV. 2002. Bacterial symbionts of the triatominae and their potential use in control of Chagas disease transmission. Annual Review of Entomology 47:123-141. 
203 Boublik Y, Jousset FX, Bergoin M. 1994. Complete nucleotide sequence and genomic 204 organization of the Aedes albopictus parvovirus (AaPV) pathogenic for Aedes aegypti larvae. 205 Virology 200:752-763.

206 Carlson J, Suchman E, Buchatsky L. 2006. Densoviruses for control and genetic manipulation of 207 mosquitoes. Advances in Virus Research 68:361-392.

208 209

210

Cirimotich CM,Dong Y, Clayton AM, Sandiford SL, Souza-Neto JA, Mulenga M, Dimopoulos G. 2011. Natural microbe-mediated refractoriness to Plasmodium Infection in Anopheles gambiae. Science 332:855-858.

Durvasula RV, Sundarum RK, Cordon-Rosales C, Pennington P, Beard CB. 2003. Rhodnius prolixus and its symbiont, Rhodococcus rhodnii: A model for paratrasgenesis control of disease transmission. 2003. In Insect symbiosis: Miller TA, Bourtzis K., Eds; CRC Press: Boca Raton.

Enayati A, Hemingway J. 2010. Malaria management: past, present, and future. Annual Review of Entomology 55:569-591.

Favia G, Ricci I, Damiani C, Raddadi N, Crotti E, Marzorati M, Rizzi A, Urso R, Brusetti L, Borin S, Mora D, Scuppa P, Pasqualini L, Clementi E, Genchi M, Corona S, Negri I, Grandi G, Alma A, Kramer L, Esposito F, Bandi C Sacchi L, Daffonchio D. 2007. Bacteria of the genus Asaia stably associate with Anopheles stephensi, an Asian malarial mosquito vector. Proceedings of the National Academy of Science USA 104:9047-9051. 
Feyereisen R. 1999. Insect P450 enzymes. Annual Review of Entomology 44:507-533.

222 Hay SI, Guerra CA, Tatem AJ, Noor AM, Snow RW. 2004. The global distribution and 223 population at risk of malaria: past, present, and future. The Lancet Infectious Diseases 4:327-336.

224 Hughes GL, Dodson BL, Johnson RM, Murdock CC, Tsujimoto H, Suzuki Y, Patt AA, Cui L, 225 Nossa CW, Barry RM, Sakamoto JM, Hornett EA, Rasgon JL. 2014. Native microbiome impedes 226 vertical transmission of Wolbachia in Anopheles mosquitoes. Proceedings of the national 227 Academy of Sciences USA 111: 12498-12503.

228 Hughes GL, Koga R, Xue P, Fukastu T, Rasgon JL. 2011a. Wolbachia infections are virulent and 229 inhibit the human malaria parasite Plasmodium falciparum in Anopheles gambiae. PLoS 230 Pathogens 7:e1002043.

231 Hughes GL, Ren X, Ramirez JL, Sakamoto JM, Bailey JA, Jedlicka AE, Rasgon JL. 2011 b. 232 Wolbachia infections in Anopheles gambiae cells: transcriptomic characterization of a novel host233 symbiont interaction. PLoS Pathogens 7:e1001296.

234 Joehanes R, Nelson JC. 2008. QGene 4.0, an extensible Java QTL-analysis platform. 235 Bioinformatics 24:2788-2789.

236 Jousset FX, Baquerizo E, Bergoin M. 2000. A new densovirus isolated from the mosquito Culex 237 pipiens (Diptera: culicidae). Virus Research 67:11-16. 
Le BV, Nguyen JB, Logarajah S, Wang B, Marcus J, Williams HP, Catteruccia F, Baxter RH. 2013. Characterization of Anopheles gambiae transglutaminase 3 (AgTG3) and its native substrate Plugin. Journal of Biological Chemistry 288:4844-4853.

Ledermann JP, Suchman EL, Black WC, Carlson JO. 2004. Infection and pathogenicity of the mosquito densoviruses AeDNV, HeDNV, and APeDNV in Aedes aegypti mosquitoes (Diptera: Culicidae). Journal of Economic Entomology 97:1828-1835.

Ng TF, Willner DL, Lim YW, Schmieder R, Chau B, Nilsson C, Anthony S, Ruan Y, Rohwer F, Breitbart M. 2011. Broad surveys of DNA viral diversity obtained through viral metagenomics of mosquitoes. PLoS ONE 6: e20579.

Noriega FG, Wang XY, Pennington JE, Barillas-Mury CV, Wells MA. 1996. Early trypsin, a female-specific midgut protease in Aedes aegypti: isolation, aminoterminal sequence determination, and cloning and sequencing of the gene. Insect Biochemistry and Molecular Biology 26:119-126.

Ren X, Hoiczyk E, Rasgon JL. 2008. Viral paratransgenesis in the malaria vector Anopheles gambiae. PLoS Pathogens 4:e1000135.

Ren X, Rasgon JL. 2010. Potential for the Anopheles gambiae densonucleosis virus (AgDNV) to act as an "evolution proof" bio-pesticide. Journal of Virology 84:7726-7729. 
257

258

Different mosquito species host Wickerhamomyces anomalus (Pichia anomala): perspectives on vector-borne diseases symbiotic control. Antonie Van Leeuwenhoek 99:43-45.

Riehle MA, Jacobs-Lorena M. 2005. Using bacteria to express and display anti-parasite molecules in mosquitoes: current and future strategies. Insect Biochemistry and Molecular Biology 35:699-707.

Suzuki Y, Niu G, Hughes GL, Rasgon JL. 2014. A viral over-expression system for the major malaria mosquito Anopheles gambiae. Scientific Reports 4:5127.

Waldock J, Olson KE, Christophides GK. 2012. Anopheles gambiae antiviral immune response to systemic O'nyong-nyong infection. PLoS Neglected Tropical Diseases 6:e1565.

Wang S, Ghosh AK, Bongio N, Stebbings KA, Lampe DJ, Jacobs-Lorena M. 2012. Fighting malaria with engineered symbiotic bacteria from vector mosquitoes. Proceedings of the National Academy of Sciences USA 109:12734-12739.

Zhai YG, Lv XJ, Sun XH, Fu SH, Gong Z, Fen Y, Tong SX, Wang ZX, Tang Q, Attoui H, 15 Liang GD. 2008. Isolation and characterization of the full coding sequence of a novel densovirus from the mosquito Culex pipiens pallens. Journal of General Virology 89:195-199. 


\section{Figure 1}

Survival of AgDNV infected or uninfected adult Anopheles gambiae.

Figure 1. Survival of AgDNV infected or uninfected adult Anopheles gambiae. Mosquitoes infected at the larvae stage with AgDNV purified from Sua5B cells (or mock infection as control; WT) were assessed for adult survivorship every 24 hours until until all the mosquitoes had perished. A, B and C refer to replicates 1, 2 and 3 respectively. 

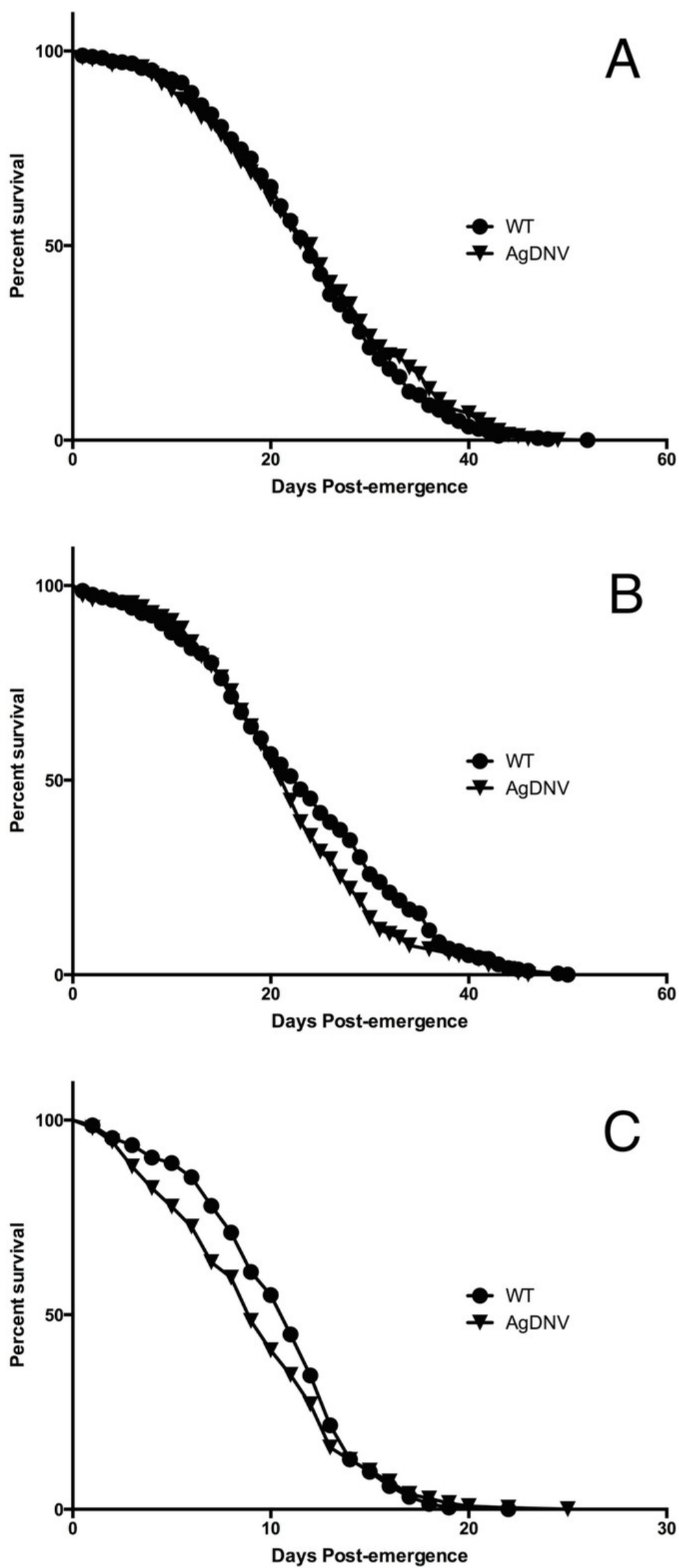

PeerJ reviewing PDF | (v2014:08:2502:1:1:NEW 28 Aug 2014) 


\section{Figure 2}

qPCR validation of microarray data

Figure 2. Validation of microarray data in DNV-infected adult An. gambiae mosquitoes. Log2 fold change values for both microarray and qPCR methods were compared for 5 selected An. gambiae genes (AMMECR1, Rel1, Rel2, cactus and caspar). $P=0.03$.

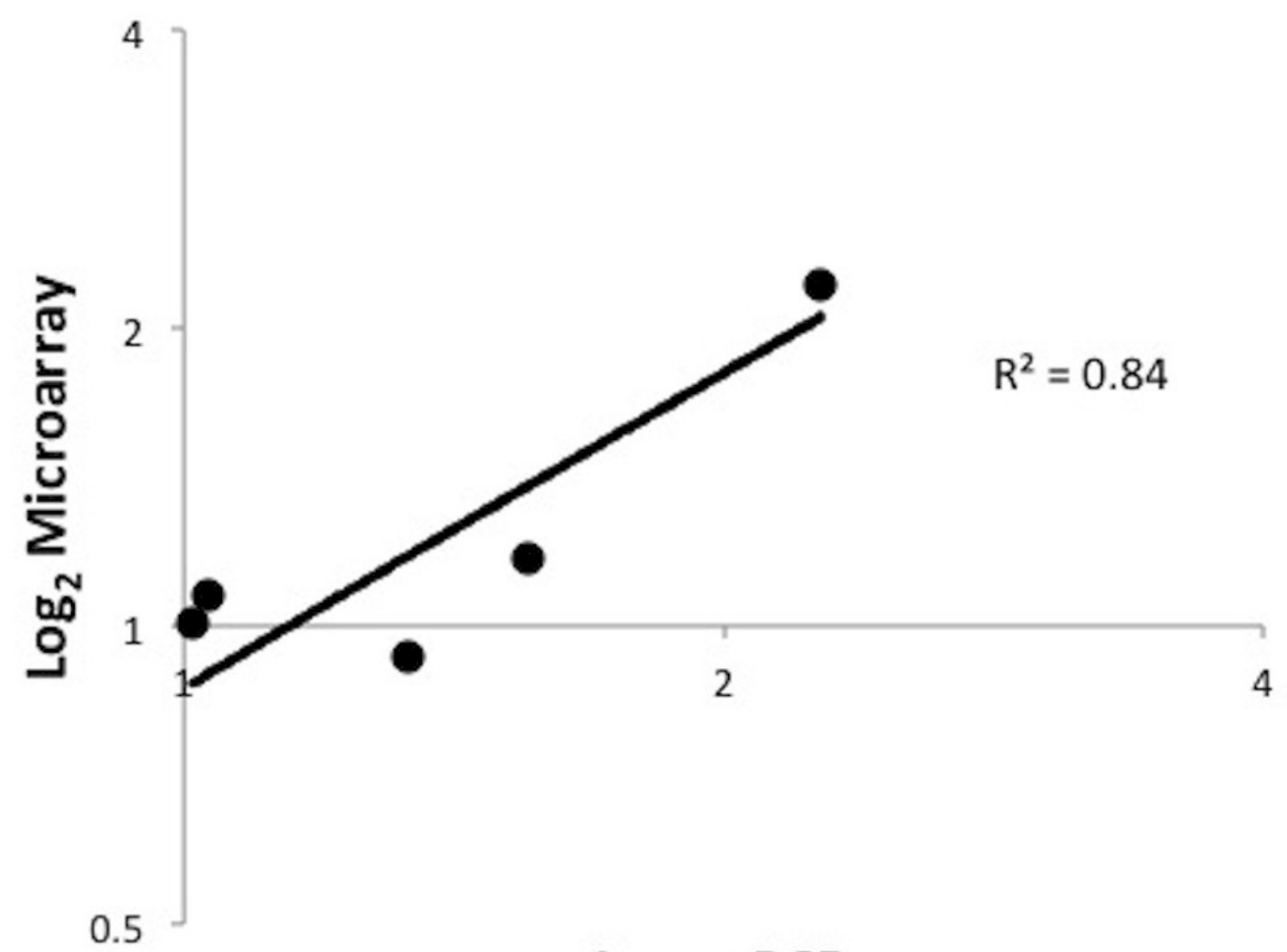

$\log _{2}$ qPCR 


\section{Table 1 (on next page) \\ PCR and $\mathrm{qPCR}$ primer sequences}

Table 1. Primers used for qPCR validation of microarray results and detection of AgDNV. 
Table 1. Primers used for qPCR validation of microarray results and detection of AgDNV.

\begin{tabular}{|c|c|c|}
\hline Gene Name & AGAP/GenBank ID\# & Primers $\left(5^{\prime}-3^{\prime}\right)$ \\
\hline Rel1 & AGAP009515 & $\begin{array}{l}\text { Forward: TCAACAGATGCCAAAAGAGGAAAT } \\
\text { Reverse: CTGGTTGAGGGATTGTG }\end{array}$ \\
\hline Caspar & AGAP006473 & $\begin{array}{l}\text { Forward: TCCACACATGCAACCTGTTT } \\
\text { Reverse: CTCGCTGCAGCACAGCGGTA }\end{array}$ \\
\hline Rel2 & AGAP006747 & $\begin{array}{l}\text { Forward: CGGTGCTCCTCGTAATGACT } \\
\text { Reverse: GTATCGTTGCGTCGGATTG }\end{array}$ \\
\hline Cactus & AGAP007938 & $\begin{array}{l}\text { Forward: GAACGGCTGCGCTTTAACA } \\
\text { Reverse: TCGTTCAAGTTCTGTGCAAGTGT }\end{array}$ \\
\hline AMMECR1 & AGAP000328 & $\begin{array}{l}\text { Forward: AAGAGACTCCCGTTTCTCGCCAAT } \\
\text { Reverse: TCGAGCCACGCTCATTGTAGAACT }\end{array}$ \\
\hline S7 & AGAP010592 & $\begin{array}{l}\text { Forward: CATTCTGCCCAAACCGATG } \\
\text { Reverse: AACGCGGTCTCTTCTGCTTG }\end{array}$ \\
\hline AgDNV capsid gene & EU233812 & $\begin{array}{l}\text { Forward: CAGAAGGATCAGGTGCAG } \\
\text { Reverse: GTTACTCCAAGAGCTACTC }\end{array}$ \\
\hline
\end{tabular}




\section{Table 2 (on next page)}

Table 2. Survival statistics for individual experimental replicates. 


\begin{tabular}{clcccc}
\hline Replicate & Treatment & $\mathrm{N}$ & Mean lifespan (days) & Chi-square & P value \\
\hline 1 & WT & 344 & 24 & 0.047 & 0.828 \\
& AgDNV & 289 & 25 & & \\
2 & & & & \\
& WT & 298 & 23 & 2.51 & 0.113 \\
& AgDNV & 199 & 22 & & \\
3 & WT & 218 & 11 & 8.92 & 0.003 \\
& AgDNV & 252 & 9 & & \\
Table 2. Survival statistics for individual experimental \\
replicates.
\end{tabular}




\section{Table 3 (on next page)}

Significantly regulated $(\mathrm{P}<0.05, \mathrm{FC}>1.75)$ genes in AgDNV-infected An. gambiae mosquitoes identified by microarray analysis. 
Table 3. Significantly regulated $(\mathrm{P}<0.05, \mathrm{FC}>1.75)$ genes in AgDNVinfected An. gambiae mosquitoes identified by microarray analysis.

\begin{tabular}{|c|c|c|c|c|c|}
\hline Affymetrix probe & $\begin{array}{l}\text { AGAP } \\
\text { Number }\end{array}$ & Gene & Function & P value & $\begin{array}{l}\text { Fold- } \\
\text { change }\end{array}$ \\
\hline Ag.3R.866.0.CDS_at & AGAP008277 & TRYPSINOGEN 2 & Peptide bond hydrolysis & 0.0148 & 2.40 \\
\hline Ag.X.430.0_CDS_at & AGAP000328 & AMME SYNDROME CANDIDATE GENE 1 & Unknown & 0.0093 & 2.21 \\
\hline Ag.X.341_CDS_a_at & AGAP001039 & CYTOCHROME P450 & Redox & 0.0327 & 2.20 \\
\hline Ag.3R.900.4_s_at & AGAP009368 & PLUGIN & Mating plug & 0.0400 & 2.00 \\
\hline Ag.2L.2922.0_a_at & AGAP007116 & CONSERVED HYPOTHETICAL PROTEIN & Unknown & 0.0399 & 1.99 \\
\hline Ag.2L.1432.0_CDS_a_at & AGAP006418 & VENOM ALLERGIN & Secreted & 0.0439 & 1.80 \\
\hline Ag.3R.292.0_CDS_a_at & AGAP009036 & $\begin{array}{l}\text { SODIUM/HYDROGEN EXCHANGER } \\
\text { CELLULAR RETINALDEHYDE BINDING }\end{array}$ & Ion transport & 0.0171 & 1.75 \\
\hline Ag.3R.1298.0_CDS_s_at & AGAP009365 & CRALBP & Binding & 0.0431 & 1.66 \\
\hline Ag.3L.707.0_UTR_at & $\begin{array}{l}\text { AGAP010732 } \\
\text { AGAP001281, }\end{array}$ & $\begin{array}{l}\text { ZINC FINGER PROTEIN } \\
\text { INWARD RECTIFIER POTASSIUM }\end{array}$ & Binding & 0.0414 & 1.66 \\
\hline Ag.2R.861.0_CDS_at & AGAP001282 & $\begin{array}{l}\text { CHANNEL } \\
\text { SPECTRIN REPEAT SYNAPTIC NUCLEAR }\end{array}$ & Ion transport & 0.0384 & -1.63 \\
\hline Ag.UNKN.1513.0_CDS_s_at & AGAP009554 & $\begin{array}{l}\text { ENVELOPE } \\
\text { SERINE/THREONINE-PROTEIN }\end{array}$ & Actin binding & 0.0228 & -1.65 \\
\hline Ag.2R.3544.0_CDS_at & AGAP004096 & PHOSPHATASE 2A SUBUNIT EPSILON & Binding & 0.0432 & -1.72 \\
\hline Ag.UNKN.2468.0_s_at & $?$ & Unknown & Unknown & 0.0012 & -1.73 \\
\hline Ag.UNKN.2158.0_CDS_at & $?$ & $\begin{array}{l}\text { Unknown } \\
\text { GLUCOSE DEHYDROGENASE }\end{array}$ & Unknown & 0.0290 & -1.78 \\
\hline Ag.2R.613.1_CDS_s_at & AGAP003785 & [ACCEPTOR $\}$ PRECURSOR & Dehydrogenase activity & 0.0049 & -1.79 \\
\hline
\end{tabular}

